SCHUSTER, Tatiana dos Santos; BITENCOURT, Caroline Muller. O movimento social negro: uma luta pelo reconhecimento de direitos e de participação do cidadão negro através do conselho municipal. Revista Eletrônica Direito e Política, Programa de Pós-Graduação Stricto Sensu em Ciência Jurídica da UNIVALI, Itajaí, v.16, n.3, $3^{\circ}$ quadrimestre de 2021. Disponível em: www.univali.br/direitoepolitica - ISSN 1980-7791.

\title{
O MOVIMENTO SOCIAL NEGRO: UMA LUTA PELO RECONHECIMENTO DE DIREITOS E DE PARTICIPAÇÃO DO CIDADÃO NEGRO ATRAVÉS DO CONSELHO MUNICIPAL
}

\author{
THE BLACK SOCIAL MOVEMENT: A STRUGGLE FOR THE RECOGNITION OF \\ RIGHTS AND PARTICIPATION OF THE BLACK CITIZENS THROUGH THE
}

MUNICIPAL COUNCIL

Tatiana dos Santos Schuster ${ }^{1}$

Caroline Muller Bitencourt ${ }^{2}$

\section{RESUMO}

O movimento negro busca não somente a participação mais efetiva dos negros nos espaços de gestão, mas o fortalecimento de partidos políticos e de governos locais que contemplam na organização do movimento social negro um forte instrumento de imposição ideológica. Diante disso questiona-se: teriam os conselhos municipais um importante papel de representatividade política na articulação das políticas públicas necessárias ao enfrentamento do que podemos chamar de racismo estrutural na sociedade brasileira? Qual é a importância dos conselhos municipais para a promoção da igualdade racial em nível local? A hipótese apresentada é que diante da conquista do movimento social em pautar a participação efetiva da população negra no exercício pleno da cidadania, articulado com a gestão pública local, é possível o alinhamento das políticas públicas de igualdade racial com a finalidade de superação das desigualdades étnicas raciais na sociedade brasileira. Em Santa Cruz do Sul, o projeto no 60/2019, proposto pelo Conselho Municipal da Igualdade Racial, encaminhado para aprovação pela Câmara Municipal, virou realidade, a partir da Lei 8.181 de 24.04.2019, que assegura $20 \%$ das vagas existentes para candidatos negros. Utiliza-se o método

\footnotetext{
1 Mestranda em Direitos Sociais e Políticas Públicas pelo Programa de Pós-Graduação em Direito da Universidade de Santa Cruz do Sul (UNISC). Pós-graduada em direito previdenciário pela Universidade de Anhanguera - LFG (2011). Graduada em Direito pela Universidade de Santa Cruz do Sul - UNISC (2009). Advogada. E-mail: tatianass.advogada@gmail.com

2 Professora do Programa de Pós-Graduação, Mestrado e Doutorado da Universidade de Santa Cruz do Sul. Pós-Doutora em Direito pela Pontifícia Universidade Católica do Paraná. Doutora e Mestre em Direito pela UNISC. Especialista em Direito Público. Membro da Rede Docente Eurolatinoamericana de Direito Administrativo. Membro da Rede de Direito Administrativo Social. Coordenadora do Grupo de pesquisa Controle Social e Administrativo de Políticas Públicas e Serviço Público. Advogada. E-mail: carolinemb@unisc.br
} 
SCHUSTER, Tatiana dos Santos; BITENCOURT, Caroline Muller. O movimento social negro: uma luta pelo reconhecimento de direitos e de participação do cidadão negro através do conselho municipal. Revista Eletrônica Direito e Política, Programa de Pós-Graduação Stricto Sensu em Ciência Jurídica da UNIVALI, Itajaí, v.16, n.3, $3^{\circ}$ quadrimestre de 2021. Disponível em: www.univali.br/direitoepolitica - ISSN 1980-7791.

dedutivo para a abordagem, o método de procedimento monográfico e a técnica de pesquisa bibliográfica.

PALAVRAS-CHAVE: Movimento Social Negro; Igualdade Racial; Conselho Municipal; Políticas Públicas.

\section{ABSTRACT}

Through this research, it will be demonstrated that the entire process of racial segregation that comes from slavery, had a direct impact on the participation of blacks in political life, which is why it is believed that municipal councils are an important space for representativeness to discuss possible public policies that aim to address this structural problem. The black movement seeks not only the effective participation of blacks in management spaces, but the strengthening of political parties and local governments that consider in the organization of the black social movement a strong instrument of ideological imposition. Given this, the question is: does municipal councils' compliance play an important role in political representation in the articulation of public policies necessary to confront what we can call structural racism in Brazilian society? What is the importance of municipal councils in promoting racial equality at the local level? The hypothesis is that given the achievement of the social movement to guide the effective participation of the black population in the full exercise of citizenship, articulated with local public management, it is possible to align public policies on racial equality with the way to overcome racial ethnic inequalities in Brazilian society. In Santa Cruz do Sul, project No. 60/2019, proposed by the City Council for Racial Equality, submitted for approval by the City Council, became a reality, based on Law 8.181 of 04.24 .2019 , which requires $20 \%$ of the existing vacancies for black candidates. The deductive method is used for the approach, the monographic procedure method and the bibliographic research technique.

KEYWORDS: Black Social Movement; Racial equality; City Council; Public policy.

\section{INTRODUÇÃO}

Desde os primeiros tempos da conquista colonial, a desigualdade tornou-se um dos pilares sobre o qual se assenta a sociedade brasileira até hoje. Um dos elementos constituintes desse pilar é a experiência do processo da escravidão, cuja influência ainda existe com todo vigor na estrutura social de todo o país. 
SCHUSTER, Tatiana dos Santos; BITENCOURT, Caroline Muller. O movimento social negro: uma luta pelo reconhecimento de direitos e de participação do cidadão negro através do conselho municipal. Revista Eletrônica Direito e Política, Programa de Pós-Graduação Stricto Sensu em Ciência Jurídica da UNIVALI, Itajaí, v.16, n.3, $3^{\circ}$ quadrimestre de 2021. Disponível em: www.univali.br/direitoepolitica - ISSN 1980-7791.

Quando da formulação da nova Constituição, em 1988, e sob a ótica dos novos contornos democráticos, houve a impressão de que os negros teriam vez e voz no cenário político formal. Buscou-se dar substrato normativo para que os negros tivessem a garantia de igualdade, especialmente com a preocupação de políticas públicas para o enfrentamento do racismo. "Contudo, não basta reconhecer, é preciso concretizar" ${ }^{\prime \prime}$. O mito da democracia racial fora denunciado pelo movimento negro, tendo em vista as suas propostas e a sua participação, o que consequentemente, desmobilizou a sociedade brasileira. Na visão do movimento, esta situação deveria ser corrigida pela intervenção do Estado na configuração das relações raciais.

Este novo cenário de organização política do país contribui para que a sociedade civil questione a sua condição enquanto ator social em relação às suas demandas. Ao mesmo tempo, o movimento negro busca mecanismos que possam atuar de forma mais efetiva por meio das estruturas de gestão pública.

Não obstante, mais especificamente, objetivou-se a análise do estudo das ações e políticas realizadas pelo movimento social negro, que travou inúmeras lutas, com o objetivo de fazer valer concretamente o que vinha determinado na legislação em relação à população negra. Ou seja, com o propósito de promover a igualdade racial.

Importante ressaltar que a temática que aqui será tratada se fundamente primeiramente, pelo fato de que mais da metade da população brasileira se auto declara negra (pretos e pardos), o que por si só, justifica a importância da análise acerca do movimento social que se tornou a principal fonte de luta pela concretização dos direitos e da cidadania da população negra.

Desde a época colonial, sua experiência social e histórica se caracterizou pelo racismo, pela violência e pela desigualdade e que, ainda no século XXI, desafia

\footnotetext{
3 BOBBIO, Norberto. A era dos direitos. Rio de Janeiro: Elsevier, 2004, p. 15.
} 
SCHUSTER, Tatiana dos Santos; BITENCOURT, Caroline Muller. O movimento social negro: uma luta pelo reconhecimento de direitos e de participação do cidadão negro através do conselho municipal. Revista Eletrônica Direito e Política, Programa de Pós-Graduação Stricto Sensu em Ciência Jurídica da UNIVALI, Itajaí, v.16, n.3, $3^{\circ}$ quadrimestre de 2021. Disponível em: www.univali.br/direitoepolitica - ISSN 1980-7791.

permanentemente a atualidade os princípios fundamentais das concepções de democracia e direitos humanos.

Assim, inúmeras foram as conquistas trazidas até aqui pelo movimento social negro, dentre elas, a possibilidade de exercício pleno da cidadania por parte da população negra, o que fomentou a criação dos conselhos de promoção da igualdade racial por parte dos poderes executivos, estaduais, distritais e municipais, dentre outras iniciativas. No presente trabalho a abordagem estará adstrita à articulação de políticas públicas e serviços destinados a superar a desigualdade étnicas existentes na sociedade brasileira através dos conselhos municipais.

\section{O MOVIMENTO SOCIAL NEGRO: BREVE HISTÓRICO}

Antes mesmo da abordagem especifica do movimento social negro, importante referir que na intenção de atingir um objetivo comum, com ideias de mudança num determinado contexto social e que tenha uma organização em grupo, com a presença de liderança ou não, têm-se a caracterização de um movimento social.

Esta organização foi a forma encontrada pela população negra para buscar reconhecimento de ganhos materiais ou até mesmo simbólicos, visto que, com a proclamação da República no Brasil em 1889, tal demanda não foi sequer cogitada. Muito pelo contrário. Segundo George Reid Andrew ${ }^{4}$, o negro era marginalizado, tanto pela forma política, pela sua não participação, social e psicológica, pela ideia de branqueamento e o racismo científico, quanto pela forma econômica, a qual o povo negro era preterido aos imigrantes europeus.

Para reverter esta marginalização da fase inicial da República, os libertos, exescravos e seus descendentes, lançaram um movimento de mobilização da raça

${ }^{4}$ ANDREWS, George Reid. O protesto político negro em São Paulo (1888-1988), Estudos Afro Asiáticos, n. 21, Rio de Janeiro, 1991, p. 32. Disponível em: http://d-scholarship.pitt.edu/21324/. Acesso em 30 jul. 2021. 
SCHUSTER, Tatiana dos Santos; BITENCOURT, Caroline Muller. O movimento social negro: uma luta pelo reconhecimento de direitos e de participação do cidadão negro através do conselho municipal. Revista Eletrônica Direito e Política, Programa de Pós-Graduação Stricto Sensu em Ciência Jurídica da UNIVALI, Itajaí, v.16, n.3, 30 quadrimestre de 2021. Disponível em: www.univali.br/direitoepolitica - ISSN 1980-7791.

negra no Brasil, criando inicialmente dezenas de grupos (grêmios, clubes ou associações) em alguns estados da nação ${ }^{5}$. O movimento negro nasce assim, em que a população negra, após a sua formal libertação da escravidão, participaram para reivindicar o reconhecimento por direitos, até então ausentes.

Conforme refere Petrônio Domingues, "o movimento negro é a luta dos negros na perspectiva de resolver seus problemas na sociedade abrangente, em particular os provenientes dos preconceitos e das discriminações raciais" ${ }^{\prime 6}$. O preconceito e a discriminação que aqui se refere, gera a exclusão do povo negro, que não possui acesso as oportunidades tanto no mercado de trabalho, como na educação, na política e na sociedade como um todo, fazendo com que permaneça às margens das condições dignas de sobrevivência.

Neste sentido, entende o movimento negro, que a "raça", 7 e, por conseguinte, a identidade racial, é utilizada não só como elemento de mobilização, mas também de mediação das reivindicações políticas". Dito de outra forma, o movimento negro parte da ideia de que, a raça é o objeto central, o fator decisivo na organização dos negros em torno de um plano de ação comum ${ }^{8}$.

De acordo com Carlos Hasenbalg ${ }^{9}$, foi a partir de meados da década de 70, que o movimento negro contemporâneo ressurge, em que o contexto brasileiro se perfazia pelo autoritarismo. A ressurreição do movimento é marcada pela construção de um segmento crescente e educado do povo negro, que em virtude

5 DOMINGUES, Petrônio. Movimento negro brasileiro: alguns apontamentos históricos. Tempo, v. 12, $\quad$ p. $100-122$, 2007.p.103. https://www.scielo.br/j/tem/a/yCLBRQ5s6VTN6ngRXQy4Hqn/abstract/?lang=pt. Acesso em 30 jul. 2021.

6 DOMINGUES, Petrônio. Movimento negro brasileiro: alguns apontamentos históricos.p.101

7 O conceito de raça é definido como uma construção social, com pouca ou nenhuma base biológica. A raça é importante porque as pessoas classificam e tratam o "outro" de acordo com as ideias socialmente aceitas. Referenda-se, aqui, a posição de Edward Telles: "o uso do termo raça fortalece distinções sociais que não possuem qualquer valor biológico, mas a raça continua a ser imensamente importante nas interações sociológicas e, portanto, deve ser levada em conta nas análises sociológicas [e históricas]". Cf. Edward Telles, Racismo à brasileira: uma nova perspectiva sociológica, Rio de Janeiro, Relume Dumará-Fundação Ford, 2003, p. 38

8 DOMINGUES, Petrônio. Movimento negro brasileiro: alguns apontamentos históricos.p. 102

9 HASENBALG, Carlos. Discriminação e Desigualdade Racial no Brasil. 2a ed. Belo Horizonte: Editora UFMG; Rio de Janeiro: Editora IUPERJ, 316 p. 2005. p.148-149. 
SCHUSTER, Tatiana dos Santos; BITENCOURT, Caroline Muller. O movimento social negro: uma luta pelo reconhecimento de direitos e de participação do cidadão negro através do conselho municipal. Revista Eletrônica Direito e Política, Programa de Pós-Graduação Stricto Sensu em Ciência Jurídica da UNIVALI, Itajaí, v.16, n.3, $3^{\circ}$ quadrimestre de 2021. Disponível em: www.univali.br/direitoepolitica - ISSN 1980-7791.

da raça, ergue-se uma barreira quando da ascensão dos seus projetos de mobilidade social.

Desta forma, através da união de forças e objetivos traçados, até hoje, o movimento social negro tem desempenhado um papel decisivo na luta pelo reconhecimento dos direitos desse grupo e pela promoção da cidadania.

Segundo Marcos Cardoso ${ }^{10}$, para o movimento negro o dia-a-dia da população negra é direcionado pela estrutura racista da sociedade brasileira. Ao se manifestar no contexto nacional e político, salientando a particularidade da luta política contra o racismo, o movimento negro tem buscado historicamente a chave para entender a realidade dos negros brasileiros.

Desta forma, o movimento negro se distingue dos demais movimentos populares da década de 70, pois a necessidade de negar a história real, bem como contribuir para a construção de uma interpretação. Portanto, a conveniência de se negar a verdadeira história e a ajudar a construir uma nova interpretação da trajetória negra no Brasil, são aspectos que diferencial o movimento negro de outros movimentos sociais e de massa dos de $1970^{11}$.

Como resultado destas lutas, de 1931 a 1937, estabeleceu-se a chamada Frente Negra Brasileira, que foi responsável pela chegada de afro brasileiros "a uma posição de proeminência no cenário político nacional, fenômeno que não fora evidenciado desde os acontecimentos ligados à abolição"12. Posteriormente, passando pelo Teatro Experimental do Negro (TEN), fundado em 1944; pela

10 CARDOSO, Marcos. O movimento negro em Belo Horizonte.: 1978-1998. Belo Horizonte: Mazza Edições, 2002. p.10.

${ }^{11}$ CARDOSO, Marcos. O movimento negro em Belo Horizonte, p.10.

12 GRAHAM, Jessica. A virada antirracista do Partido Comunista do Brasil, a Frente Negra Brasileira e a Ação Integralista Brasileira na década de 1930. In: GOMES, Flávio dos Santos \& DOMINGUES, Petrônio (org.). Políticas da Raça: experiências e legados da abolição e da pós-emancipação no Brasil. São Paulo: Selo Negro Edições, 2014, pp. 353-402. p. 353 
SCHUSTER, Tatiana dos Santos; BITENCOURT, Caroline Muller. O movimento social negro: uma luta pelo reconhecimento de direitos e de participação do cidadão negro através do conselho municipal. Revista Eletrônica Direito e Política, Programa de Pós-Graduação Stricto Sensu em Ciência Jurídica da UNIVALI, Itajaí, v.16, n.3, $3^{\circ}$ quadrimestre de 2021. Disponível em: www.univali.br/direitoepolitica - ISSN 1980-7791.

fundação do Movimento Negro Unificado (MNU), em 1978; até a Marcha Zumbi dos Palmares, em $1995^{13}$.

Desde então, o movimento negro tem procurado enfatizar as características estruturais do racismo e a exclusão resultante de diferentes maneiras, embora muitas vezes procedam de forma bastante oculta. Como destaca Luís S. Cardoso de Oliveira14 "uma das características das práticas de discriminação indireta vigentes no Brasil é que ela costuma aparecer de maneira dissimulada, sendo por vezes de difícil identificação mesmo para aqueles que sofrem na pele os seus efeitos".

Assim, se apropriando do mito da democracia racial, indivíduos brasileiros de diversas culturas, costumam ignorar as óbvias características raciais dos papéis sociais atribuíveis às pessoas, desde o "elevador de serviço" ao perfil dos "suspeitos" que passam a ser monitorados pelos sistemas de segurança pública e privada, do século XIX ao XXI. Mais uma vez, reporta-se ao autor supracitado: "o aspecto mais impressionante do racismo à brasileira está no fato de ele ser (radicalmente) relativizava, mesmo quando envolve atores com convicções racistas assumidas"15.

Importa-se referir a importância da centralidade política e social edificada através da luta do movimento social negro, particularmente a partir da promulgação da Constituição Federal de 1988, o qual concedeu às comunidades quilombolas o direito territorial; assim como a intervenção direta na construção de políticas públicas de Estado, com vistas à promover a igualdade racial, manifestada através das ações afirmativas no campo da educação, especialmente as cotas para universidades federal e instituições de ensino técnico de nível médio (Lei 12.711);

13 DE CASTRO CRUZ, Laila Caroline; COTA, Luiz Gustavo Santos. O movimento social negro. CIÊNCIA DINÂMICA, v. 17, n. 1, p. 75-96, 2020. Disponível em: http://revista.faculdadedinamica.com.br/index.php/cienciadinamica/article/view/30. Acesso em 6 set. 2021. p.78

14 OLIVEIRA, Luís R. Cardoso de. Racismo, direitos e cidadania. Estudos Avançados.vol.18, n.50, pp. 81-93, 2004. Disponível em: <http://www.scielo.br/pdf/ea/v18n50/a09v1850.pdf>. Acesso em: 29 jul. 2021 , p. 82.

15 OLIVEIRA, Luís R. Cardoso de. Racismo, direitos e cidadania. p. 82. 
SCHUSTER, Tatiana dos Santos; BITENCOURT, Caroline Muller. O movimento social negro: uma luta pelo reconhecimento de direitos e de participação do cidadão negro através do conselho municipal. Revista Eletrônica Direito e Política, Programa de Pós-Graduação Stricto Sensu em Ciência Jurídica da UNIVALI, Itajaí, v.16, n.3, $3^{\circ}$ quadrimestre de 2021. Disponível em: www.univali.br/direitoepolitica - ISSN 1980-7791.

bem como para os concursos no serviço público federal (Lei 12.990); pela promulgação do Estatuto da Igualdade Racial (Lei 12.288) que, além de outras medidas, implementou o Sistema Nacional de Promoção da Igualdade Racial (SINAPIR), órgão responsável pela organização e elaboração de políticas públicas e serviços "destinados a superar as desigualdades étnicas existentes no País, prestados pelo poder público federal", bem como o fomento à criação dos conselhos de promoção da igualdade racial por parte das autoridades administrativas estaduais, distritais e municipais; dentre outras iniciativas ${ }^{16}$.

Referidas conquistas estão intrinsicamente relacionadas às lutas dos movimentos sociais, em perspectiva interseccional (negros, mulheres, homossexuais, pessoas com deficiência, entre outros), principalmente no sentido de ampliar direitos sociais, buscando a consolidação de direitos de grupos específicos, e até mesmo a necessidade de reafirmação de políticas públicas de natureza redistributiva e / ou de reconhecimento ${ }^{17}$.

O tema relativo à estas questões, tem sido alvo de pesquisas de diferentes áreas do conhecimento, particularmente os que se relacionam aos domínios das Ciências Humanas e Sociais, tais como o Direito, a Sociologia, a Antropologia, a Ciência Política e a História. Neste sentido, cabe ressaltar que "a busca pela democratização dos movimentos tornou-se fundamental a partir do século XXI e ela se manifesta no reconhecimento e na identidade coletiva dos diferentes movimentos sociais que se espalham no mundo e na sociedade"18.

Desta forma, para manter aquilo que já foi reconhecido, os direitos conquistados, é preciso lutar constantemente, a fim de que fase da subordinação seja

\footnotetext{
16 DE CASTRO CRUZ, Laila Caroline; COTA, Luiz Gustavo Santos. O movimento social negro.p.80. 17 SALVADOR, A. F.; PAIVA, Â. R.; NEVES, A. V. Ações afirmativas, movimentos sociais e reconhecimento - Estudos contemporâneos. O Social em Questão-Ano XX -no 37-p. 9-10Jan a abr. 2017. Disponível em: http://osocialemquestao.ser.pucrio.br/media/OSQ_37_Apresenta\%C3\%A7\%C3\%A30\%20(2).pdf.Acesso em: 1 ago. 2021. p.9.

18 SALVADOR, A. F.; PAIVA, Â. R.; NEVES, A. V. Ações afirmativas, movimentos sociais e reconhecimento. p.10.
} 
SCHUSTER, Tatiana dos Santos; BITENCOURT, Caroline Muller. O movimento social negro: uma luta pelo reconhecimento de direitos e de participação do cidadão negro através do conselho municipal. Revista Eletrônica Direito e Política, Programa de Pós-Graduação Stricto Sensu em Ciência Jurídica da UNIVALI, Itajaí, v.16, n.3, $3^{\circ}$ quadrimestre de 2021. Disponível em: www.univali.br/direitoepolitica - ISSN 1980-7791.

ultrapassada, mantendo-se assim a defesa contra quaisquer tentativas de derrubada das práticas democráticas, que já tem o seu lugar na agenda política da Estado ${ }^{19}$.

Percebe-se que, se hoje a população negra, bem como os integrantes de diversos grupos sociais, invoca o direito de permanecer e lutar pelo seu espaço, deve-se ao trabalho árduo e incansável dos movimentos sociais, especialmente o movimento social negro.

Politicamente, o movimento realizou manifestações e organizou ações da população negra, no tocante ao combate ao racismo estrutural, contestando e rompendo o mito da democracia racial, entendida enquanto narrativa oficial do passado e da identidade nacional brasileira do presente. Além disso, o movimento negro atuou de forma precisa e importante quando do processo de redemocratização do país, momento em que se estabeleceu a construção de espaços e mecanismo de reconhecimento e cidadania 20 .

Outro marco importante, idealizado pelo movimento negro, ocorreu com a celebração do tricentenário da morte de Zumbi, em novembro de 1995, em que foi organizada a "Marcha Zumbi dos Palmares Contra o Racismo, pela Cidadania e a Vida". Foram mais de 20 mil pessoas que estiveram presente em Brasília, o que caracterizou um importante marco político, no que se refere à articulação política da luta antirracista, em que um dos seus resultados, foi a entrega, ao então Presidente da República Fernando Henrique Cardoso, o Programa de Superação do Racismo e da Desigualdade Racial, documento que apresentava

\footnotetext{
19 SALVADOR, A. F.; PAIVA, Â. R.; NEVES, A. V. Ações afirmativas, movimentos sociais e reconhecimento. p.10.

20 GOMES, Nilma Lino. O movimento negro no Brasil: ausências, emergências e a produção dos saberes. Política \& Sociedade. Volume 10. No18, p. 142-143. Abril de 2011. Disponível em: <https://periodicos.ufsc.br/index.php/politica/article/viewFile/19037/17537>. Acesso em: 29 jul. 2021
} 
SCHUSTER, Tatiana dos Santos; BITENCOURT, Caroline Muller. O movimento social negro: uma luta pelo reconhecimento de direitos e de participação do cidadão negro através do conselho municipal. Revista Eletrônica Direito e Política, Programa de Pós-Graduação Stricto Sensu em Ciência Jurídica da UNIVALI, Itajaí, v.16, n.3, $3^{\circ}$ quadrimestre de 2021. Disponível em: www.univali.br/direitoepolitica - ISSN 1980-7791.

uma análise acerca dos desafios e desigualdade enfrentados pelos negros brasileiros, exigindo-se do Estado ações específicas de combate racismo ${ }^{21}$.

Já no século XXI, a atuação dos movimentos sociais negros tem um significado decisivo, para que suas demandas possam ser atendidas na forma de políticas públicas nacionais. No ano de 2001, a "3a Conferência Mundial contra o Racismo, a Discriminação Racial, a Xenofobia e Formas Correlatas de Intolerância", realizada pela Organização das Nações Unidas (ONU) na cidade de Durban, na África do Sul, a "Conferência Nacional contra o Racismo e a Intolerância", realizada na Universidade do Estado do Rio de Janeiro (UERJ), bem como a "Conferência Intergovernamental Regional das Américas", realizada no Chile, são vistos como significativos marcos no progresso da luta do movimento negro a partir da exposição no âmbito nacional e internacional das desigualdades raciais existentes no Brasil 22 .

Importante mencionar que, tratando-se de movimento, surge em 2013, o "Black Live Matter", (Vidas Negras Importam) criado por três mulheres negras, é um movimento ativista internacional, com origem na comunidade afro-americana, em resposta à absolvição do policial George Zimmerman, que atirou no jovem afroamericano Trayvon Martin, de apenas 17 anos. Black Lives Matter Global Network Foundation, Inc., é uma organização global nos Estados Unidos, Reino Unido e Canadá, cuja missão é erradicar a supremacia branca e construir poder local para intervir na violência infligida às comunidades negras pelo estado e vigilantes ${ }^{23}$.

Referida organização, mesmo que iniciado nos Estados Unidos, no ano de 2016, também alcançou outros países como Brasil, África do Sul e Austrália, onde ativistas tomaram as ruas e as redes sociais em solidariedade às vítimas da violência policial. Eles adotaram o grito de guerra "Black Lives Matter" (Vidas

${ }^{21}$ GOMES, Nilma Lino. O movimento negro no Brasil: ausências, emergências e a produção dos saberes. p.142.

22 DE CASTRO CRUZ, Laila Caroline; COTA, Luiz Gustavo Santos. O movimento social negro.p.83. 23 MATTER, Black Lives. Vidas pretas importam. Disponível em: https://blacklivesmatter.com/about/. Acesso em: 31 ago.2021. 
SCHUSTER, Tatiana dos Santos; BITENCOURT, Caroline Muller. O movimento social negro: uma luta pelo reconhecimento de direitos e de participação do cidadão negro através do conselho municipal. Revista Eletrônica Direito e Política, Programa de Pós-Graduação Stricto Sensu em Ciência Jurídica da UNIVALI, Itajaí, v.16, n.3, 30 quadrimestre de 2021. Disponível em: www.univali.br/direitoepolitica - ISSN 1980-7791.

Negras Importam) para amplificar suas lutas em seus próprios países e para apontar o que consideram uma abordagem hipócrita da imprensa e do governo ${ }^{24}$.

No contexto brasileiro, acrescenta-se ainda como conquista, a promulgação da Lei 12.228, no ano de 2010, que instituiu o Estatuto da Igualdade Racial, no intuito de "garantir à população negra a efetivação da igualdade de oportunidades, a defesa dos direitos étnicos individuais, coletivos e difusos e o combate à discriminação e às demais formas de intolerância étnica"25.

O documento composto por 65 artigos, é vasto por conta das inúmeras temáticas em relação à população negra e às desigualdades por ela sofridas, invocando assim o chamamento necessário das políticas públicas voltadas à educação, cultura, saúde e trabalho, bem como a defesa das comunidades quilombolas e adeptos das religiões de matriz africana.

Para Joana Stelzer e Everton Gonçalves ${ }^{26}$, "o Estatuto estabeleceu a mais sólida conquista normativa na sociedade brasileira", trazendo para o Estado o dever de combater o racismo, com base no papel proativo de promoção da igualdade, tanto na esfera municipal, estadual e federal.

Uma das políticas públicas que é promovida pelo Estatuto da Igualdade Racial, é a instituição do Sistema Nacional de Promoção da Igualdade Racial (SINAPIR), "como forma de organização e de articulação voltadas à implementação do conjunto de políticas e serviços destinados a superar as desigualdades étnicas existentes no País, prestados pelo poder público federal", além do incentivo à

\footnotetext{
24 MATTER, Black Lives. Vidas pretas importam.

25 BRASIL. Lei 12.288 , de 20 de julho de 2010. Institui o Estatuto da Igualdade Racial. Diário Oficial da República Federativa do Brasil, Brasília, DF, 20 jul. 2010.Disponivel em: http://www.planalto.gov.br/ccivil_03/_ato2007-2010/2010/lei/l12288.htm. Acesso em: $1^{0}$ set. 2021.

26 STELZER, Joana; GONÇALVES, Everton das Neves. Igualdade racial e movimento negro: direito e política em perspectiva histórica. Revista Eletrônica Direito e Política, Programa de PósGraduação Stricto Sensu em Ciência Jurídica da UNIVALI, Itajaí, v.11, n.1, p.448-449. 10 quadrimestrede2016.

Disponível em:<https://siaiap32.univali.br/seer/index.php/rdp/article/view/8801/4897> Acessado em: 3 ago. 2021.p.448.
} 
SCHUSTER, Tatiana dos Santos; BITENCOURT, Caroline Muller. O movimento social negro: uma luta pelo reconhecimento de direitos e de participação do cidadão negro através do conselho municipal. Revista Eletrônica Direito e Política, Programa de Pós-Graduação Stricto Sensu em Ciência Jurídica da UNIVALI, Itajaí, v.16, n.3, $3^{\circ}$ quadrimestre de 2021. Disponível em: www.univali.br/direitoepolitica - ISSN 1980-7791.

instituição de conselhos de promoção à igualdade racial, por parte do poder executivo, nos estados, Distrito Federal e municípios, de caráter "permanente e consultivo, compostos por igual número de representantes de órgãos e entidades públicas e de organizações da sociedade civil representativas da população negra", devendo ser priorizada pelo estado a transmissão de recursos para sustentar os programas e atividades pressupostos no Estatuto aos entes federados que tenham criado conselhos ${ }^{27}$.

A instituição de conselhos municipais de promoção da igualdade racial, é tema para o próximo tópico.

\section{CONSELHOS MUNICIPAIS DE PROMOÇÃO DA IGUALDADE RACIAL: ESPAÇO DE PODER, DECISÃO E ARTICULAÇÃO PARA POLÍTICAS PÚBLICAS}

A articulação da sociedade civil na sua relação com o Estado, passou a ser diferenciada nos últimos dez anos. Observa-se que o poder local tem sua fundamental importância, a presença de regimes mais democráticos, a descentralização como processo de valor, uma nova conexão entre o poder público, sociedade e atividade produtiva, a preservação ambiental, como objeto de atenção, bem como uma qualidade de vida melhor. Tais elementos para são de suma importância apara a construção de espaços públicos participativos ${ }^{28}$.

No que se refere à organização institucional das esferas de gestão, a ex ministra da SEPPIR, Matilde Ribeiro ${ }^{29}$, destaca que as políticas públicas, legislações e ações

\footnotetext{
27 BRASIL. Lei 12.288, de 20 de julho de 2010. Institui o Estatuto da Igualdade Racial.

28 PEREIRA, André Luis. Mecanismos de Promoção da Igualdade Racial em nível local: uma análise do processo de implementação das políticas de promoção da igualdade racial em Porto Alegre (2004-2014). Tese (Doutorado) Universidade Federal do Rio Grande do Sul. Porto Alegre: 2016.p.101.

29 RIBEIRO, Matilde. As políticas de igualdade racial no Brasil. No 35. São Paulo: Fundação Friedrich Ebert, 2009. Disponível em: https://library.fes.de/pdf-files/bueros/brasilien/06429.pdf. Acesso em 6 set. 2021.
} 
SCHUSTER, Tatiana dos Santos; BITENCOURT, Caroline Muller. O movimento social negro: uma luta pelo reconhecimento de direitos e de participação do cidadão negro através do conselho municipal. Revista Eletrônica Direito e Política, Programa de Pós-Graduação Stricto Sensu em Ciência Jurídica da UNIVALI, Itajaí, v.16, n.3, $3^{\circ}$ quadrimestre de 2021. Disponível em: www.univali.br/direitoepolitica - ISSN 1980-7791.

afirmativas fazem parte da sociedade civil e dos movimentos governamentais, que mudaram a situação da vida política do país.

Esta afirmação mostra que a maioria dos gestores tem uma clara intenção de "ouvir" a sociedade civil nas questões relacionadas à redução das desigualdades e tratamento igualitário às mais diversas classes sociais. Conforme defendido por Leonardo Avritzer e Maria de Lourdes Pereira30, a marca do processo de democratização no Brasil é a ação coletiva dos atores sociais que, em sua luta contra o autoritarismo, limitam o poder do Estado, geram potencial organizacional no campo da sociedade civil e estabelecem alternativas de organização social e política.

Assim, os conselhos municipais, são órgãos os quais é possibilitado o exercício da participação do cidadão e o controle por partes destes, principalmente nos processos decisórios quem envolvem políticas públicas que visam atender na maioria das vezes seus próprios interesses. Isto significa dizer que as demandas da sociedade são trazidas para a sociedade, através do próprio cidadão e também da própria sociedade civil.

Nesse sentido, as políticas públicas a fim de serem ampliadas e sempre renovadas, necessitam da articulação dos atores coletivos para que se expandam os limites da agenda pública, bem como do seu conteúdo. Conforme refere André Luis Pereira ${ }^{31}$, "a consolidação de demandas apresentadas por segmentos exclusivos no conjunto das sociedades só se confirma a partir da participação cidadã na formulação de políticas públicas e decisões estatais, bem como, com a valorização da deliberação pública". Este recurso confere permissão aos entes envolvidos, a fim de invocar a democrática participativa como instrumento de qualificação da gestão pública, o que proporciona a manutenção de um sistema que permite

30 AVRITZER, Leonardo; PEREIRA, Maria de Lourdes Dolabela. Democracia, participação e instituições híbridas. Teoria \& Sociedade, n. especial, p. 16-41, 2005.

31 PEREIRA, André Luis. Mecanismos de Promoção da Igualdade Racial em nível local: uma análise do processo de implementação das políticas de promoção da igualdade racial em Porto Alegre (2004-2014). p. 102. 
SCHUSTER, Tatiana dos Santos; BITENCOURT, Caroline Muller. O movimento social negro: uma luta pelo reconhecimento de direitos e de participação do cidadão negro através do conselho municipal. Revista Eletrônica Direito e Política, Programa de Pós-Graduação Stricto Sensu em Ciência Jurídica da UNIVALI, Itajaí, v.16, n.3, $3^{\circ}$ quadrimestre de 2021. Disponível em: www.univali.br/direitoepolitica - ISSN 1980-7791.

experiências que conferem a implementação de alternativas de gestão mais igualitárias.

É preciso ressaltar que, por mais que seja flexível os espaços políticos na contemporaneidade, ainda remanescem fortes resistências na luta pela implementação de políticas públicas voltadas para a redução da desigualdade entre as diferentes classes sociais. Isto porque, existe toda uma questão cultural, um racismo impregnado e uma sociedade que nega sua existência, e por conta disso, não vê os motivos para combater o que não existe.

Importante também lembrar que o espaço político brasileiro, carece que maior representação de certos segmentos sociais, principalmente aqueles que foram excluídos historicamente dos processos decisórios, no tocante a estrutura político formal. Destaca-se que a própria formação social e política do Brasil acabou por privilegiar a classe dominante, pois estabeleceu vantagens sociais e econômicas aos diversos níveis da sociedade brasileira. Neste sentido, resta evidente a desvantagem social e econômica da população negra que não ocupa estes espaços $^{32}$.

Tal diagnóstico tem total relação com a falta de aceitação de que o Brasil é um país com estratificações raciais, o que impede a ascensão e inserção do povo negro nestes espaços de poder.

Atualmente, a relação entre o Estado e a sociedade enfrenta novos desafios. Quanto maior a expansão da prática democrática, maior a necessidade de uma participação qualificada da sociedade civil e, portanto, ampliou-se a diversidade de sujeitos expressos de formas mais complexas. Conforme aponta Oliveira:

Os sujeitos coletivos potencializam a participação, conferindoIhe um caráter político transformador. Assim, a atuação nos conselhos setoriais de políticas públicas, nas conferências das cidades, no orçamento participativo, nos processos de eleição

\footnotetext{
32 PEREIRA, André Luis. Mecanismos de Promoção da Igualdade Racial em nível local: uma análise do processo de implementação das políticas de promoção da igualdade racial em Porto Alegre (2004-2014). p. 103.
} 
SCHUSTER, Tatiana dos Santos; BITENCOURT, Caroline Muller. O movimento social negro: uma luta pelo reconhecimento de direitos e de participação do cidadão negro através do conselho municipal. Revista Eletrônica Direito e Política, Programa de Pós-Graduação Stricto Sensu em Ciência Jurídica da UNIVALI, Itajaí, v.16, n.3, $3^{\circ}$ quadrimestre de 2021. Disponível em: www.univali.br/direitoepolitica - ISSN 1980-7791.

de prioridades para o município, e demandas da comunidade são exemplos de participação política transformadora da cultura, política tradicional, do poder público centralizado, onde o indivíduo não passa da condição de cliente da política. Essas práticas de participação fortalecem o surgimento de valores de solidariedade, de ação coletiva, de participação ativa, de prática política cidadã cotidiana. Essa noção de cultura política deve ser considerada não como uma variável independe, mas um fator impulsionador da participação política e da construção da democracia em suas diversas dimensões ${ }^{33}$.

Estes novos desafios traçados pela sociedade e pelo Estado, são decorrentes das desigualdades sociais, civis e políticas constatadas, associada com a insatisfação da relação entre a sociedade civil e o Estado, nos anos 70 e 80, o que estimulou algumas transformações.

Disso decorreu a união da sociedade civil com os movimentos sociais com o propósito de democratizar a participação nos processos de tomada de decisões sobre as políticas públicas, fazendo com que se encontre na agenda política, a própria definição do que é democracia, inovando os princípios basilares da relação entre sociedade e Estado ${ }^{34}$.

Cumpre referir a Constituição Federal de 1988, que marcou o processo de democratização, trouxe em seu ordenamento a possibilidade da participação dos entes municipais, caracterizando assim o exercício de uma cidadania ativa, com supedâneo nas políticas sociais de desenvolvimento, tendo como objetivo a integralização como garantia da cidadania plena, constituindo-se assim estruturas de co-participação entre o Estado a sociedade para gestão dessas políticas ${ }^{35}$.

33 OLIVEIRA, Luís R. Cardoso de. Racismo, direitos e cidadania. p. 72.

${ }^{34}$ CUNHA, Eleonora Schettini Martins. Participação política e o enfrentamento da questão social: o potencial dos conselhos de políticas e do orçamento participativo no Brasil. In: VIII Congresso Luso-afro-brasileiro de Ciências Sociais. 2004. Disponível em: https://www.passeidireto.com/arquivo/88064383/cunha-eleonora-a-participacao-politica-e-oenfrentamento-da-questao-social. Acesso em: 6 set. 2021.p. 2.

35 CARVALHO, Juvenilda et al. Conselhos municipais: sua contribuição para o desenvolvimento local. Anais do Enanpad, v. 23, 1999. Disponível em: http://www.anpad.org.br/admin/pdf/enanpad1999-ap-10.pdf. Acesso em 04 ago. 2021. p. 2. 
SCHUSTER, Tatiana dos Santos; BITENCOURT, Caroline Muller. O movimento social negro: uma luta pelo reconhecimento de direitos e de participação do cidadão negro através do conselho municipal. Revista Eletrônica Direito e Política, Programa de Pós-Graduação Stricto Sensu em Ciência Jurídica da UNIVALI, Itajaí, v.16, n.3, 30 quadrimestre de 2021. Disponível em: www.univali.br/direitoepolitica - ISSN 1980-7791.

Da institucionalização da participação da sociedade, trazido pela Constituição Federal de 1988, através dos conselhos gestores, também decorre disso, o princípio da descentralização, que se dá a partir da introdução desta participação ao ordenamento jurídico, impulsionando assim a construção de recursos de participação como os orçamentos participativos e os conselhos municipais ${ }^{36}$.

Assim, quando do final da década de 80 e início da de 90, se instaura os Conselhos Municipais, que se consubstancial como umas das maiores experiências de participação democrática, com articulação em nível federal, e atuante nas temáticas da saúde, educação, cultura, meio ambiente, transporte e tantos outros $^{37}$. Instaura-se assim, o verdadeiro núcleo representação de um verdadeiro diálogo entre a sociedade civil e o ente estatal, em canais públicos e plurais.

Pontua-se assim, que os conselhos municipais de controle social desempenham um papel fundamental na consolidação das políticas públicas, bem como na integração entre as diferentes áreas, realizando fiscalizações e controlando os gastos públicos. Isto demonstra a significativa importância do papel dos conselhos municipais na análise tanto no âmbito social como político, e mais especificamente, do Conselho Municipal de Promoção da Igualdade Racial - COMPIR ${ }^{38}$.

Nesse sentido, o objetivo da discussão e implementação de políticas públicas é garantir que a população negra tenha oportunidades iguais de acesso a determinados espaços sociais, pois, como se repetiu, sua experiência é justamente marcada pela injustiça. Portanto, tais políticas tendem a redistribuir e restaurar processos históricos que geraram desigualdades, como a escravidão e o racismo resultante ${ }^{39}$.

36 MOTA, Aurea. Sobre Contexto(s) e História(s): o centralismo como limite concreto à possibilidade de efetivação de práticas de participação política ampliada. In: AVRITZER, Leonardo (Org.). A dinâmica da participação local no Brasil. São Paulo: Cortez, 2010. p. 314

37TATAGIBA, Luciana. Conselhos gestores de políticas públicas e democracia participativa: aprofundando o debate. Revista de Sociologia e Política, n. 25, p. 209-213, 2005. p. 209.

38 DE CASTRO CRUZ, Laila Caroline; COTA, Luiz Gustavo Santos. O movimento social negro.p.86 ${ }^{39}$ ALBUQUERQUE, Rosa Almeida e PEDRON, Cristiane Drebes. Os objetivos das ações afirmativas em uma Instituição de Ensino Superior (IES) pública brasileira: a percepção da 
SCHUSTER, Tatiana dos Santos; BITENCOURT, Caroline Muller. O movimento social negro: uma luta pelo reconhecimento de direitos e de participação do cidadão negro através do conselho municipal. Revista Eletrônica Direito e Política, Programa de Pós-Graduação Stricto Sensu em Ciência Jurídica da UNIVALI, Itajaí, v.16, n.3, $3^{\circ}$ quadrimestre de 2021. Disponível em: www.univali.br/direitoepolitica - ISSN 1980-7791.

O apontamento acima mostra que a maior penetração da administração pública nas questões relacionadas à classe social das minorias torna a cidadania efetiva, pois esses grupos fazem suas demandas aos entes públicos e procuram obter resultados significativos para eles ${ }^{40}$.

Desta forma, o Conselho Municipal de Promoção da Igualdade Racial (COMPIR), especificamente no âmbito local de Santa Cruz do Sul-RS, tem por objetivo contribuir na formulação, na implementação e no monitoramento da Política Municipal de Promoção da Igualdade Racial. O COMPIR é um órgão deliberativo, normativo, monitorador, que tem a finalidade de propor políticas públicas de igualdade racial com ênfase na população negra e outros segmentos étnicos, no âmbito Municipal. Regido pela Lei Municipal n 7.467 de 16 de dezembro de 2015, em seu artigo $5^{\circ}$ (alterado em 1612.2021), dispõem sobre a composição do plenário do Conselho:

I - órgãos governamentais:

a) Dois membros titulares e respectivos suplentes indicados pela Secretara Municipal de Educação;

b) Um membro titular e respectivo suplente indicado pela Secretaria Municipal da Fazenda;

c) Um membro titular e respectivo suplente indicado pela Secretaria Municipal de Habitação, Desenvolvimento Social e Esporte;

d) Um membro titular e respectivo suplente indicado pela Secretaria Municipal da Cultura;

e) Um membro titular e respectivo suplente indicado pela Secretaria Municipal da Saúde;

comunidade acadêmica. Revista brasileira de Estudos Pedagógicos, Brasília, v. 99, n. 251, p. 5473, jan./abr. 2018. Disponível em: <http://www.scielo.br/pdf/rbeped/v99n251/2176-6681rbeped-99-251-54.pdf>. Acesso em: 03 de ago. 2021.

40 PEREIRA, André Luis. Mecanismos de Promoção da Igualdade Racial em nível local: uma análise do processo de implementação das políticas de promoção da igualdade racial em Porto Alegre (2004-2014). p. 103. 
SCHUSTER, Tatiana dos Santos; BITENCOURT, Caroline Muller. O movimento social negro: uma luta pelo reconhecimento de direitos e de participação do cidadão negro através do conselho municipal. Revista Eletrônica Direito e Política, Programa de Pós-Graduação Stricto Sensu em Ciência Jurídica da UNIVALI, Itajaí, v.16, n.3, 30 quadrimestre de 2021. Disponível em: www.univali.br/direitoepolitica - ISSN 1980-7791.

II - 6 (seis) membros de entidades da Sociedade Civil, de comprovada atuação na defesa da comunidade negra e de outros segmentos étnico-raciais da população santacruzense.

O conselho municipal de promoção da igualdade racial, se mostram um aliado do povo negro da cidade, que não apenas contesta as condições de desvantagens econômica, social e política que os grupos de poder lhe impõem, mas também lutam em torno desta questão, passando a apresentar uma série de propostas que podem representar, concretamente, um passo fundamental para a plena igualdade entre os cidadãos ${ }^{41}$.

O que se estabelece a partir daí é uma verdadeira parceria visando deliberar acerca do gerenciamento das políticas públicas, ao mesmo tempo em que acontece o controle social. "Os conselhos gestores de políticas públicas são canais efetivos de participação, que permitem estabelecer uma sociedade na qual a cidadania deixe de ser apenas um direito, mas uma realidade"42 (BRASIL, 2021). Ou seja, é o meio pelo qual é fortalecida a participação da população de forma democrática, em que suas demandas devem ser formuladas e implementadas através das políticas públicas.

Como bem nos assegura Geraldo César Diegues ${ }^{43}$, pode-se dizer que os conselhos municipais funcionam como canal de interlocução entre a sociedade e o poder público, onde se discute, participa e delibera sobre a forma de atuação do governo. É um espaço que se percebe a verdadeira prática da cidadania, o que concretiza o

\footnotetext{
41 PEREIRA, André Luis. Mecanismos de Promoção da Igualdade Racial em nível local: uma análise do processo de implementação das políticas de promoção da igualdade racial em Porto Alegre (2004-2014). p. 107.

42 BRASIL. Portal da Transparência. Controle Social - Conselhos municipais e controle social. Disponível em: http://www.portaltransparencia.gov.br. Acesso em: 5 ago. 2021.

${ }^{43}$ DIEGUES, Geraldo César. $\mathbf{O}$ controle social e participação nas políticas públicas: o caso dos conselhos gestores municipais. NAU Social, v. 4, n. 6, p. 82-99, 2013. Disponível em: O controle social e participação nas políticas públicas: o caso dos conselhos gestores municipais. Disponível em file://C:/Users/Win\%2010/Downloads/31241-Texto\%20do\%20Artigo-110750-1-1020130531.pdf. Acesso em: 04 ago. 2021. p. 1.
} 
SCHUSTER, Tatiana dos Santos; BITENCOURT, Caroline Muller. O movimento social negro: uma luta pelo reconhecimento de direitos e de participação do cidadão negro através do conselho municipal. Revista Eletrônica Direito e Política, Programa de Pós-Graduação Stricto Sensu em Ciência Jurídica da UNIVALI, Itajaí, v.16, n.3, 30 quadrimestre de 2021. Disponível em: www.univali.br/direitoepolitica - ISSN 1980-7791.

Estado Democrático de Direito. Neste contexto, fica claro que os conselhos municipais acabam por produzir a inclusão e social e o respeito as minorias.

A vinculação com a administração municipal tem a função de garantir a execução de planos e projetos que envolvam a cidadania plena do povo negro. Também é objetivo instituir políticas municipais que promovam a igualdade racial, que sirva como documento básico na elaboração dos planos de ação e transforme as demandas e necessidades da população negra enquanto atores sociais e coletivos, participantes da comunidade municipal ${ }^{44}$.

A formulação e implementação de políticas públicas, geralmente carecem de engajamento dos municípios para que estas se efetivem de forma qualificada e eficaz. A análise de Maria Teresa M. Kerbauy ${ }^{45}$ aponta sobre o poder local que, entre as décadas de 1970 e 1970, houve o aparecimento de espaços locais municipais como territórios políticos étnicos, culturais, sociais e econômicos, justamente quando se deu a transição democrática entre as décadas de 1970 e 1980.

Neste sentido, Kerbauy ${ }^{46}$ (2000), ainda ressalta que o governo municipal enquanto espaço político institucional, em que representações se expressam, as alianças, os confrontos e as organizações sociais de interesses, de forças e organizações sociais que marcam e moldam o território local em escala regional e nacional, assumem fundamental importância na concretização dos processos e de gestão pública.

\footnotetext{
44 PEREIRA, André Luis. Mecanismos de Promoção da Igualdade Racial em nível local: uma análise do processo de implementação das políticas de promoção da igualdade racial em Porto Alegre (2004-2014). p. 113.

45 KERBAUY, Maria Teresa Miceli. A morte dos coronéis: política e poder local. Araraquara: $\mathrm{FCL}$ UNESP, 2000.Disponível em: https://books.google.com.br/books/about/A_morte_dos_coron\%C3\%A9is.html?id=nCvfPAAACAAJ \&redir_esc=y.Acesso em 5 ago. 2021.
}

46 KERBAUY, Maria Teresa Miceli. A morte dos coronéis: política e poder local. 
SCHUSTER, Tatiana dos Santos; BITENCOURT, Caroline Muller. O movimento social negro: uma luta pelo reconhecimento de direitos e de participação do cidadão negro através do conselho municipal. Revista Eletrônica Direito e Política, Programa de Pós-Graduação Stricto Sensu em Ciência Jurídica da UNIVALI, Itajaí, v.16, n.3, $3^{\circ}$ quadrimestre de 2021. Disponível em: www.univali.br/direitoepolitica - ISSN 1980-7791.

Assim, a criação de um diálogo com a gestão pública municipal é um cenário de oportunidade para incorporar a temática racial como objeto de implementação de políticas públicas.

\section{CONSIDRAÇÕES FINAIS}

No presente trabalho buscou-se demonstrar o papel fundamental que ocupou o movimento negro para que as poucas, mas significativas conquistas para que o povo negro hoje tivesse vez e voz.

Como destacado, foi possível identificar que a formulação das políticas públicas de promoção da igualdade racial sempre esteve alinhada com o debate proposto pela Constituição Federal de 1988, o qual também possibilitou a implementação de conselhos municiais, com objetivo de promover a participação da sociedade civil para o exercício da pela cidadania. A isto se deve à importante atuação política do movimento social negro.

De maneira geral, os dados examinados indicam que o movimento negro se organizou no que se refere à luta pela constituição de políticas públicas pensadas em sintonia com as discussões tecidas pela Constituição Federal, mesmo que enfrentando possíveis dificuldades de organização interna e articulação com o poder público local, indicando a necessidade de um novo e contínuo esforço de fortalecimento de tais políticas.

\section{REFERÊNCIAS DAS FONTES CITADAS}

ALBUQUERQUE, Rosa Almeida e PEDRON, Cristiane Drebes. Os objetivos das ações afirmativas em uma Instituição de Ensino Superior (IES) pública brasileira: a percepção da comunidade acadêmica. Revista brasileira de Estudos Pedagógicos, Brasília, v. 99, n. 251, p. 54-73, jan./abr. 2018. Disponível em: <http://www.scielo.br/pdf/rbeped/v99n251/2176-6681rbeped-99-251-54.pdf>. Acesso em: 03 de ago. 2021. 
SCHUSTER, Tatiana dos Santos; BITENCOURT, Caroline Muller. O movimento social negro: uma luta pelo reconhecimento de direitos e de participação do cidadão negro através do conselho municipal. Revista Eletrônica Direito e Política, Programa de Pós-Graduação Stricto Sensu em Ciência Jurídica da UNIVALI, Itajaí, v.16, n.3, $3^{\circ}$ quadrimestre de 2021. Disponível em: www.univali.br/direitoepolitica - ISSN 1980-7791.

ANDREWS, George Reid, "O protesto político negro em São Paulo (18881988)", Estudos Afro Asiáticos, n. 21, Rio de Janeiro, 1991, p. 32. Disponível em: http://d-scholarship.pitt.edu/21324/. Acesso em 30 jul. 2021.

AVRITZER, Leonardo; PEREIRA, Maria de Lourdes Dolabela. Democracia, participação e instituições híbridas. Teoria \& Sociedade, n. especial, p. 16$41,2005$.

BOBBIO, Norberto. A era dos direitos. Rio de Janeiro: Elsevier, 2004.

BRASIL. Portal da Transparência. Controle Social - Conselhos municipais e controle social. Disponível em: <http://www.portaltransparencia.gov.br>. Acesso em: 05 ago. 2021.

BRASIL. Lei 12.288, de 20 de julho de 2010. Institui o Estatuto da Igualdade Racial. Diário Oficial da República Federativa do Brasil, Brasília, DF, 20 jul. 2010.Disponivel em: http://www.planalto.gov.br/ccivil_03/_ato20072010/2010/lei/l12288.htm. Acesso em: $1^{0}$ set. 2021.

BRASIL. Lei 12.711, de 29 de agosto de 2012. Dispõe sobre o ingresso nas universidades federais e nas instituições federais de ensino técnico de nível médio e dá outras providências. Diário Oficial da República Federativa do Brasil, Brasília, DF, 29 ago. 2012. Disponível em: http://www.planalto.gov.br/ccivil_03/_ato2011-

2014/2012/lei/l12711.htm. Acesso em: $1^{0}$ set. 2021.

BRASIL. Lei 12.990, de 9 de junho de 2014. Dispõe sobre a reserva aos negros $20 \%$ (vinte por cento) das vagas oferecidas nos concursos públicos para provimento de cargos efetivos e empregos públicos no âmbito da administração pública federal, das autarquias, das fundações públicas, das empresas públicas e das sociedades de economia mista controladas pela União. Diário Oficial da República Federativa do Brasil, Brasília, DF, 9 jun. 2014. Disponível em: http://www.planalto.gov.br/ccivil_03/_ato20112014/2014/lei/l12990.htm. Acesso em: $1^{0}$ set. 2021.

CARDOSO, Marcos. O movimento negro em Belo Horizonte.: 1978-1998. Belo Horizonte: Mazza Edições, 2002. p.10.

CARVALHO, Juvenilda et al. Conselhos municipais: sua contribuição para o desenvolvimento local. Anais do Enanpad, v. 23, 1999. Disponível em: http://www.anpad.org.br/admin/pdf/enanpad1999-ap-10.pdf. Acesso em 04 ago. 2021. 
SCHUSTER, Tatiana dos Santos; BITENCOURT, Caroline Muller. O movimento social negro: uma luta pelo reconhecimento de direitos e de participação do cidadão negro através do conselho municipal. Revista Eletrônica Direito e Política, Programa de Pós-Graduação Stricto Sensu em Ciência Jurídica da UNIVALI, Itajaí, v.16, n.3, $3^{\circ}$ quadrimestre de 2021. Disponível em: www.univali.br/direitoepolitica - ISSN 1980-7791.

CUNHA, Eleonora Schettini Martins. Participação política e o enfrentamento da questão social: o potencial dos conselhos de políticas e do orçamento participativo no Brasil. In: VIII Congresso Luso-afro-brasileiro de Ciências Sociais. 2004.

DE CASTRO CRUZ, Laila Caroline; COTA, Luiz Gustavo Santos. O movimento social negro. CIÊNCIA DINÂMICA, v. 17, n. 1, p. 75-96, 2020. Disponível em:

http://revista.faculdadedinamica.com.br/index.php/cienciadinamica/article /view/30. Acesso em: 6 set 2021.

DIEGUES, Geraldo César. O controle social e participação nas políticas públicas: o caso dos conselhos gestores municipais. NAU Social, v. 4, n. 6, p. 82-99, 2013. Disponível em: O controle social e participação nas políticas públicas: o caso dos conselhos gestores municipais. Disponível em: file://C:/Users/Win\%2010/Downloads/31241-Texto\%20do\%20Artigo110750-1-10-20130531.pdf. Acesso em: 04 ago. 2021

DOMINGUES, Petrônio. Movimento negro brasileiro: alguns apontamentos históricos. Tempo, v. 12, p. 100-122, 2007. Disponível em: https://www.scielo.br/j/tem/a/yCLBRQ5s6VTN6ngRXQy4Hqn/abstract/?la $\mathrm{ng}=$ pt. Acesso em 30 jul. 2021

GOMES, Nilma Lino. O movimento negro no Brasil: ausências, emergências e a produção dos saberes. Política \& Sociedade. Volume 10. No18, p. 142143. Abril de 2011. Disponível em: <https://periodicos.ufsc.br/index.php/politica/article/viewFile/19037/1753 7>. Acesso em: 29 jul. 2021

GRAHAM, Jessica. A virada antirracista do Partido Comunista do Brasil, a Frente Negra Brasileira e a Ação Integralista Brasileira na década de 1930. In: GOMES, Flávio dos Santos \& DOMINGUES, Petrônio (org.). Políticas da Raça: experiências e legados da abolição e da pós-emancipação no Brasil. São Paulo: Selo Negro Edições, 2014, pp. 353-402

HASENBALG, Carlos. Discriminação e Desigualdade Racial no Brasil. 2a ed. Belo Horizonte: Editora UFMG; Rio de Janeiro: Editora IUPERJ, 316 p. 2005. p.148-149.

KERBAUY, Maria Teresa Miceli. A morte dos coronéis: política e poder local. Araraquara: FCL UNESP, 2000.

MATTER, Black Lives. Vidas pretas importam. Disponível em: https://blacklivesmatter.com/about/. Acesso em: 31 ago.2021. 
SCHUSTER, Tatiana dos Santos; BITENCOURT, Caroline Muller. O movimento social negro: uma luta pelo reconhecimento de direitos e de participação do cidadão negro através do conselho municipal. Revista Eletrônica Direito e Política, Programa de Pós-Graduação Stricto Sensu em Ciência Jurídica da UNIVALI, Itajaí, v.16, n.3, $3^{\circ}$ quadrimestre de 2021. Disponível em: www.univali.br/direitoepolitica - ISSN 1980-7791.

MOTA, Aurea. Sobre Contexto(s) e História(s): o centralismo como limite concreto à possibilidade de efetivação de práticas de participação política ampliada. In: AVRITZER, Leonardo (Org.). A dinâmica da participação local no Brasil. São Paulo: Cortez, 2010. p. 314.

OLIVEIRA, Luís R. Cardoso de. Racismo, direitos e cidadania. Estudos Avançados.vol.18, n.50, pp. 81-93, 2004. Disponível em: <http://www.scielo.br/pdf/ea/v18n50/a09v1850.pdf>. Acesso em: 29 jul. 2021

PEREIRA, André Luis. Mecanismos de Promoção da Igualdade Racial em nível ocal: uma análise do processo de implementação das políticas de promoção da igualdade racial em Porto Alegre (20042014). Tese (Doutorado) Universidade Federal do Rio Grande do Sul. Porto Alegre: 2016.

RIBEIRO, Matilde. Análise e propostas: as políticas de igualdade racial no Brasil. No 35. São Paulo: Fundação Friedrich Ebert, 2009.

SALVADOR, A. F.; PAIVA, Â. R.; NEVES, A. V. Ações afirmativas, movimentos sociais e reconhecimento -Estudos contemporâneos. O Social em Questão-Ano XX-no 37-p. 9-10Jan a abr. 2017. Disponível em: http://osocialemquestao.ser.pucrio.br/media/OSQ_37_Apresenta\%C3\%A7\%C3\%A30\%20(2).pdf.Acesso em: 1 ago. 2021.

STELZER, Joana; GONÇALVES, Everton das Neves. Igualdade racial e movimento negro: direito e política em perspectiva histórica. Revista Eletrônica Direito e Política, Programa de Pós-Graduação Stricto Sensu em Ciência Jurídica da UNIVALI, Itajaí, v.11, n.1, p.448-449. ${ }^{0}$ quadrimestrede2016.

Disponível em: <https://siaiap32.univali.br/seer/index.php/rdp/article/view/8801/489 7> Acessado em: 3 ago. 2021.

TATAGIBA, Luciana. Conselhos gestores de políticas públicas e democracia participativa: aprofundando o debate. Revista de Sociologia e Política, n. 25, p. 209-213, 2005. 